JOURNAL DE PHYSIQUE IV

Colloque C4, supplément au Journal de Physique III, Vol. 1, novembre 1991

\title{
STABILISATION PROCESSES IN A CANTIM ALLOY
}

\author{
I. HURTADO (1), S. VAN HUMBEECK and L. DELAEY \\ Catholic University Leuven, Dept. Metallurgy and Materials Engineering, de Croylaan 2, B-3001 \\ Heverlee, Belgium
}

\begin{abstract}
The effect of post-quench heat treatments on the transformation characteristics and on the physical properties of a fine grained $\mathrm{Cu}-\mathrm{Al}-\mathrm{Ni}-\mathrm{Mn}$ - $\mathrm{Ti}$ high temperature shape memory alloy are investigated by means of differential scanning calorimetry (DSC), X-ray powder diffraction, thermoelectric power (TEP) and hardness measurements. The changes during a posterior ageing in the martensite state, just below the As temperature, are described by three stages, and explained in terms of order and precipitation processes.
\end{abstract}

\section{1.- Introduction}

Cu-Al-Ni shape memory alloys are known to exhibit a better thermal stability than $\mathrm{Cu}-\mathrm{Zn}$ Al alloys $/ 1 /$. This characteristic makes them more prone to be used in applications above 373 $\mathrm{K}$, which is the limit for the $\mathrm{Cu}-\mathrm{Zn}-\mathrm{Al}$ alloys.

Thermal stability of $\mathrm{Cu}-\mathrm{Al}-\mathrm{Ni}$ alloys has been investigated mostly during ageing in $\beta$ phase $/ 2 /-15 /$, and the change in transformation temperatures has been mainly attributed to two kinds of processes: ordering and precipitation. The reported features are very dependent both on the alloy composition relative to the correspondent eutectoid composition and on the ageing temperature at which the experiment has been carried out. The lower the ageing temperature, below $500 \mathrm{~K}$, and the nearer the alloy composition is to the eutectoid, the less prone is the alloy to precipitation an thus the less overlap with the ordering processes.

The thermal stability of the martensite phase has been less studied $15 /, 16 /$. In all the works the observed increase in the transformation temperatures during ageing has been attributed to ordering processes. In the present work, the stability of the martensite phase during ageing at 393 and $413 \mathrm{~K}$ is studied for a Cu-Al-Ni-Ti-Mn (CANTiM) alloy.

\section{2.- Experimental method and material}

Commercially hot rolled $1.1 \mathrm{~mm}$ thick sheet of composition $80.1 \mathrm{Cu}-11.9 \mathrm{Al}-5 \mathrm{Ni}-2 \mathrm{Mn}$ $1 \mathrm{Ti}(w \mathrm{t} \%)$ was provided by KOBE Steel Ltd (Japan). The composition of this alloy corresponds to an hypoeutectoid, and the as rolled material shows elongated grains with average dimensions of $240 * 200 * 130 \mu^{3}$.

For the Differential Scanning Calorimetry (DuPont 2100) technique, samples in the form of rectangular prisms (approx. $3 * 3 * 1.1 \mathrm{~mm}^{3}$ and mass of about $50 \mathrm{mg}$ ) were cut from the sheet and heat treated as will be explained further. A heating or cooling rate of $2^{\circ} \mathrm{C}$ per minute was used when details of the transformation peak shape were required, and at $10^{\circ} \mathrm{C}$ per minute otherwise, using a liquid $\mathrm{N}_{2}$ cooling device (LNCA). The cycling range was usually between 70 and $220^{\circ} \mathrm{C}$, and at least two consecutive cycles were always carried out for each sample.

(1) On leave from: Basque Country University, Dept. Condensed Matter Physics, PO. Box 644, SP-48080 Bilbao, Spain 
X-Ray diffraction profiles were obtained at room temperature (martensite phase) from samples of $21 * 9 * 1.1 \mathrm{~mm}^{3}$ by means of a Philips powder diffraction apparatus. Cu K $\alpha$ radiation at $34 \mathrm{Kv}$ and $20 \mathrm{~mA}$ were used. Generally, the range $2 \theta=20$ to $100^{\circ}$ was scanned using a $2 \theta=0.02^{\circ}$ step method, and a time of 2 sec per step.

Thermoelectrical Power measurements (TEP) were realized on samples of $100 * 4 \star 1.1$ $\mathrm{mm}^{3}$ which were placed between two $\mathrm{Cu}$ blocks, held at $15^{\circ} \mathrm{C}$ and $25^{\circ} \mathrm{C}$ respectively, which act as electrical and thermal contacts.

Vickers Microhardness tests were done on the samples after the X-ray scan. The load was $200 \mathrm{gr}$ and at least five indentations were realized at random on each sample.

Phase identification and microstructure were studied using optical (Leitz Metalloplan) and Scanning Electronic Microscopy (SEM-Philips 515), including EDX analysis. The voltage used in the SEM was $20 \mathrm{KV}$ and the spot size was between 20 and $100 \mathrm{~nm}$

\section{Heat treatments}

Before any other specific heat treatment, all the material in this investigation was annealed at $700^{\circ} \mathrm{C}$ for $30 \mathrm{~min}$ plus subsequently water quenched to room temperature (treatment A). The martensitic transiormation temperatures after this heat treatment are: $M s=125^{\circ} \mathrm{C}, \mathrm{Mf}=100^{\circ} \mathrm{C}, \mathrm{As}=128^{\circ} \mathrm{C}, \mathrm{Af}=143^{\circ} \mathrm{C}$, and the microstructure consists of thin lamella of martensite, identified by Transmission Electron Microscopy as M18R, and precipitates of the so called $X$ phase.

Following, the samples were aged at $300^{\circ} \mathrm{C}$ ( $\beta$ phase) for 15,30 or $60 \mathrm{~min}$. respectively $(A B, A C, A E)$, and subsequently water quenched to room temperature. With these treatments the As transformation temperature increases up to $140^{\circ} \mathrm{C}(\mathrm{AB}), 150^{\circ} \mathrm{C}(\mathrm{AC})$ and $165^{\circ} \mathrm{C}(\mathrm{AE})$. These aged samples were further aged at $120^{\circ} \mathrm{C}$ or $150^{\circ} \mathrm{C}$ (martensite state) for different times up to several months.

\section{3.- Results, ageing at $150^{\circ} \mathrm{C}$}

The results for the series $A B$ and $A C$, aged at $120^{\circ} \mathrm{C}$, are qualitatively similar to the ones at $150^{\circ} \mathrm{C}$. Consequently only these last ones will be presented in detail here.

\section{Differential Scanning Calorimetry (DSC)}

The effects of the ageing at $150^{\circ} \mathrm{C}$ up to 5 days are shown in fig. 1 . The first curve corresponds to a sample not aged in martensite phase. The direct transformation temperatures remained unchanged in subsequent cycles.

1) For ageing times lower than 2.5 hours $(9)^{(1)}$ : The first retransformation peak appears at lowers temperature and with a lower endothermal heat than the second retransformation peak $\left[Q\left(1^{9}\right)=10.5 \mathrm{~J} / \mathrm{g}\right.$ and $\left.\mathrm{Q}\left(2^{\circ}\right)=12.5 \mathrm{~J} / \mathrm{g}\right]$. The first retransformation is more jerky and occurs over a broader range of temperatures as compared to the second one. On the other hand, the exothermal heat during the forward transformation is almost constant for all direct transformations and equal to $12.5 \mathrm{~J} / \mathrm{g}$.

2) As the ageing time increases the first retransformation peak becomes narrower. Two consecutive stages may be observed: for ageing times lower than about 7 min (6) the narrowing is due to a shift of the Af temperature with As nearly constant. For longer times the main contribution to the narrowing process is the shift of As to higher temperatures.

3) Initially, the second retransformation peak shifts to lower temperatures and becomes narrower with increasing ageing, but however stabilises with further ageing.

4) For longer ageing times, the first retransformation peak shifts towards higher transformation temperatures. Two consecutive stages may be observed: For ageing times larger than 2.5 hours (9) and up to 2 days (12), the shift of the first peak, with a width approx. constant, is accompanied by an increase of its endothermal heat in respect to the consecutive transformations, whose value remains constant. For ageing times longer than 2 days (12),

(1) The number between brackets after a time value is the neperian logarithm of the time expressed in seconds. 
apart from the important increment in the transformation temperatures, it is observed that the endothermic heat of the first retransformation peak only increase very slightly.

(1) Wide and jerky first peak

(2)

\section{Narrowing of} first peak

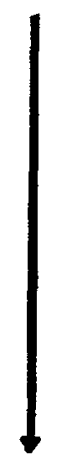

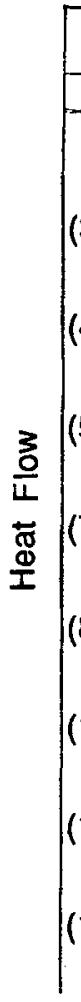

fig. 1 Evolution of DSC curves with ageing time up to 5 day. Serie $A E$ (ageing at $150^{\circ} \mathrm{C}$ )

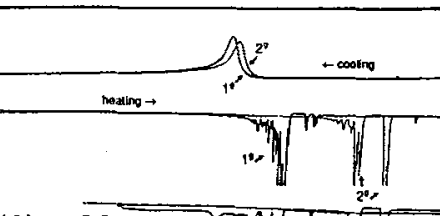

(3)

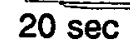

(4)

(5)

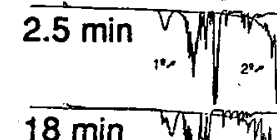

(8)

(10)

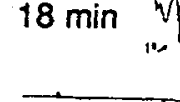

$50 \min$

,

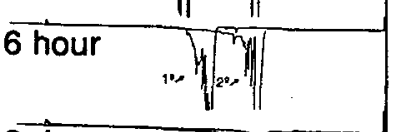

(12)

2 day

(13)
(3)

Shift of second reverse peak to lower temperatures

Scan rate: $2^{\circ} \mathrm{C}$ per min

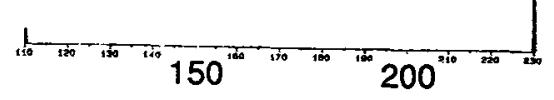

(4)

Shift of first peak to higher temperatures

\section{Temperature $/{ }^{\circ} \mathrm{C}$}

\section{Thermoelectric Power (TEP)}

The results of the Thermoelectric Power measurements, fig. 2, can be divided into three stages: For short ageing times, less than $2.5 \mathrm{~min}(5)$, TEP is almost constant and the value is smaller than that for an unaged in martensite state sample. For ageing times between $2.5 \mathrm{~min}$ (5) and till about 2 days (12), an S-shape increment is observed. For longer ageing times there is a steep increase in the TEP.

\section{X-Ray Diffraction}

Apart from the martensite and $X$-phase peaks, no extra peaks were detected in the $X$ Ray diffraction profiles, even after long ageing times. The (040) and (320) martensite peaks were used in determining the monoclinic distortion of the martensite lattice $p_{2}=\sin ^{2} \theta(040)$ $\sin ^{2} \theta(320) / 7 /$. In the present study the $\rho_{2}$ parameter, fig. 3 , decreases slowly with increasing ageing times up to 2 days (12), for longer ageing there is a step in $\rho_{2}$. The distortion which corresponds to the peaks (122) and (202), $\rho_{1}=\sin ^{2} \theta(122)-\sin ^{2} \theta(202)$, was calculated and related to the measured transformation temperatures. The result is shown in fig. 4.

Hardness observed.

The results of the microhardness experiments are presented in fig. 5 . No change is

Scanning electron and light optical microscopy

Self accommodating martensite and X-phase particles are observed, but not evolution of the microstructure during the ageing treatments in martensite phase. 


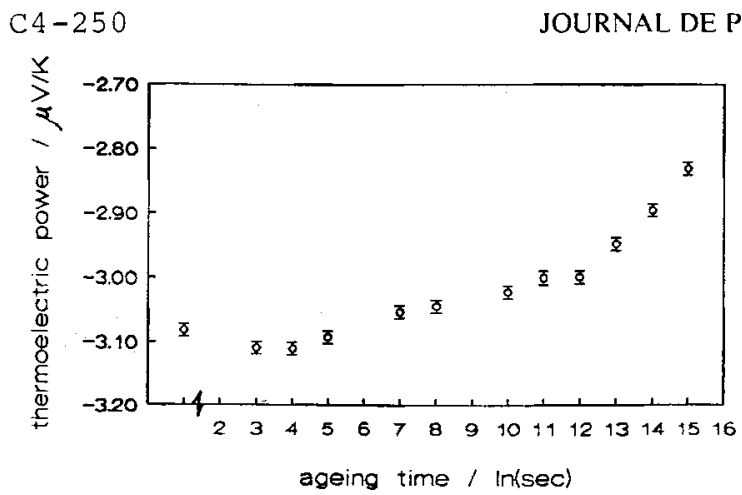

fig.2 Evolution of the Thermoelectrical Power (TEP) during ageing at $150^{\circ} \mathrm{C}$

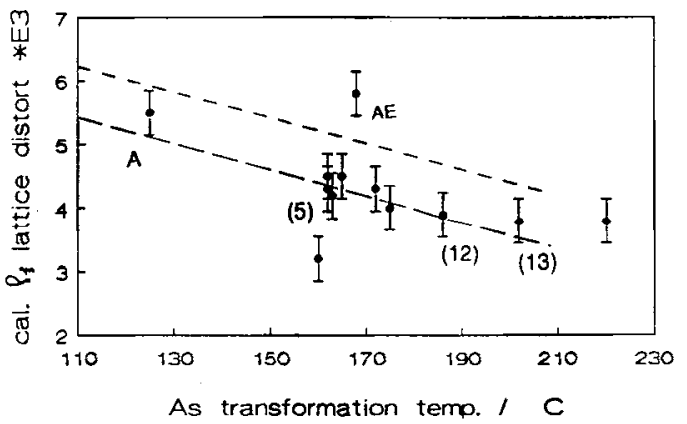

fig.4 Relation between the As temperature and the $p_{1}$ calculated distortion, ageing at $150^{\circ} \mathrm{C}$. The serrated line stands for the $M s-p_{1}$ relation as given in $/ 18 /$ for changes in composition in the $\mathrm{Cu}-\mathrm{Zn}-\mathrm{Al}$ system. The doted line corresponds to the As- $\rho_{1}$ relation in $/ 4 /$ for a $\mathrm{Cu}$ - $\mathrm{Al}-\mathrm{Ni}$ alloy.

Consequently, the process of stabilisation at $150^{\circ} \mathrm{C}$ can be divided into three consecutive stages:

1.- This first stage, short ageing times, till approx. $7 \mathrm{~min}(6)$, is characterised by a near constant value of the Thermoelectric Power. The temperatures Af and $A p^{(2)}$ of the jerky first retransformation peak, shift towards lower temperatures, the transformation interval Af-As decreases, and the Ap corresponding to the second cycle also shifts to lower temperatures. The endothermic heat of the first retransformation is smaller than the corresponding values in the following cycles. This is accompanied by a decrease of the lattice distortion what is related to a more hexagonal disposition of the atoms in the basal plane.

2.- The second stage, at intermediate ageing times, between 7 minutes (6) and about 2 days (12), is characterised by an S-shape increase in TEP, increments in $A s\left(1^{8}\right), A p\left(1^{\circ}\right)$ and constant transformation temperatures for the second and consecutive cycles. The Af-As transformation interval remains constant and the $Q\left(1^{\circ} \mathrm{cycle}\right)$ increases till it attains the value of $\mathrm{Q}\left(2^{2}\right.$ cycle $)$ for 2 days of ageing. In this stage, a linear relationship between the mean calculated lattice distortion parameter and the $A s\left(1^{9}\right)$ temperatures is observed.

3.- In the final stage, corresponding to ageing times longer than 2 days (12), there is an important increment in the TEP value. The experimental lattice distortion drops to lower values although the calculated one is approximately constant. The Af-As transformation interval increases.

(2) Ap is the temperature corresponding to $50 \%$ of the transformation 


\section{4.- Discussinn}

Due to the quenching from $700^{\circ} \mathrm{C}$ the initial material is not in equilibrium: Rapacioli et al described this state as short range disorder in a long range ordered matrix $/ 8 /$. The material is also characterised by the presence of antiphase domains, and high vacancy concentration.

In the Cu-Al-Ni system, a decrement of the transformation temperatures with increasing quenching rate is observed. This indicates that a better $\mathrm{DO}_{3}$ order corresponds with a higher transformation temperature $19 /$. In the present work, after quenching, the material was aged at $300^{\circ} \mathrm{C}$ which is below the $\mathrm{DO}_{3}$ ordering temperature for this alloy. Accordingly a better $\mathrm{DO}_{3}$ order is expected, along with an increment in the transformation temperatures, as it is indeed observed /10/. Thus, the material, before aged in martensite state, is supposed to have a $\mathrm{DO}_{3}$ order that is more complete for longer ageing time in $\beta$ phase (serie $A E$ ).

When comparing the results of DSC for samples aged for different times in the $\beta$ phase it is observed that the jerkiness of the retransformation peaks decreases with the ageing time in $\beta$ phase. This irregular heat flow is explained by Dunne et al $/ 11 /, / 12 /$ as $M n$-vacancy barriers which oppose the first retransformation. The jerkiness disappears after a reversion to $\beta$ phase, and thus the barriers are removed according to these authors. In the present case it is observed that the second retransformation peak is also jerky, especially for the lowest ageing times in $\beta$ phase. The difference can be due to the smaller DSC scan speed used in the present experiment, which allows a better resolution of individual events.

The remaining fluctuations in heat flow at temperatures approaching $A f$, in the second retransformation, are explained by the same authors /11/ as due to interface pinning by $X s$ particles which oppose the retransformation. The presence of Xs particles is reported to be more notable in samples quenched from intermediate temperatures, as in the present work 112\%. Another explanation of the irregular heat flow, also observed in Cu-Al-Ni alloys, is the formation and reversion of individual plates or plate pairs $/ 13 /, 114 /$.

"Accommodation" of the martensite would be helped by the quenched stresses and the quenched-in vacancies, and would have the effect of raise the Af transformation temperature for the first retransformation cycle.

First stage: short ageing times in the martensite phase.- This could be considered as an "incubation" time. After an initial slight drop of the TEP value after very short ageing times at $150^{\circ} \mathrm{C}$ the TEP value remains constant, as well as the As transformation temperature.

The presence of the second retransformation peak at higher temperatures could be explained as a recovery of order in the $\beta$ phase. The posterior shift to lower temperatures and stability of this second peak can be explained taking into account that this recovery process in $\beta$ phase is a diffusion process. As such, it is aided, along with longer times and higher temperatures, by the presence of vacancies. The annealing of vacancies during long ageing times in martensite state would slow down the kinetics of the recovery, and so a smaller $\beta$ order would be inherited by the martensite.

The start of the next stage seems to be postponed till the vacancies annihilation process has progressed to a final state. The process seems to be depending on the ageing temperature and not so much dependent of the degree of $\mathrm{DO}_{3}$ order.

Still another effect to be taken into account would be the elastic energy stored in the material during the first transformation. This energy would help the first retransformation to begin at lower temperatures. It could be that during retransformation to $\beta$ phase the origin of this elastic energy would disappear (possible lost by coherency of precipitates?) and thus the second retransformation temperatures would be higher those of the first heating. In this line of thinking, the lower endothermic heat observed in the first cycle than in the second is explained by Ortin et al /15/ as a larger contribution of the elastic strains in the process.

Second stage: intermediate ageing times in the martensite phase.- The S-shaped increase in the Thermoelectric Power measurements is similar to the one observed by other authors $/ 16 /$, and can be attributed to a increasing short range disorder process. This is also the interpretation that has been given by the authors that have studied ageing processes in martensite phase in Cu-Al-Ni alloys $/ 6 /, / 5 /$. In the present results one observes an increase of the $A s$ and $A p$ corresponding to the first retransformation transformation while the Af-As value remains constant. These observations agree with changes in order [84Sca]. They are also in agreement with the linear relationship observed between the lattice distortion and the $A s\left(1^{\circ}\right)$ temperatures for the $\mathrm{Cu}-\mathrm{Zn}-\mathrm{Al}$ system $/ 18$ / and for a Cu-Al-Ni alloy after different heat 
treatments /4/. A higher hexagonality and a lower monoclinic distortion was also pointed out by Delaey et al /19/for the ageing process in martensite state of a $\mathrm{Cu}-\mathrm{Zn}-\mathrm{Al}$ alloy.

Third stage: long ageing times in the martensite pibses. - In this stage, precipitation of equilibrium phases might start, although X-Ray diffraction not indicate such a formation of any additional phase. It is therefore difficult to conclude that the observed increase in transformation temperatures is due either to a matrix depletion of solute or to a pinning process. Wu and Wayman /20/ analysing the results on ageing martensite in a Cu-Zn-Al alloy, speculate that $\mathrm{Al}$ rich clustering may occur in defects at a much earlier stage before being physically significant enough to be detected.

Any coherent formation of precipitates in the martensite would have the effect of an increase of the Af-As temperature interval and endothermic values of the first retransformation. Clearly one observes an increase of the Af-As temperature interval from $10^{\circ} \mathrm{C}$ for 17 hours of ageing $\left(2^{\circ}\right.$ stage) to $20^{\circ} \mathrm{C}$ for 1 month. The increase in the $Q\left(1^{\circ}\right)$ value is very small, but could be covered by the decrease due to less transformed material. Nevertheless $Q\left(1^{\circ}\right)>Q\left(2^{\circ}\right)$ in this third stage.

The clear increase of the TEP value also sustains the hypothesis of the beginning of a precipitation process. For the second retransformation transformation the temperatures remain constant. Irregularities in the heat flow, even observed at $10^{\circ} \mathrm{C}$ per minute of scan rate in DSC, support the idea of some kind of opposition to the martensite interface movement.

\section{5.- References}

11 N.F. Kennon, D.P. Dunne and L. Middleton, Metall. Trans. A 13, 551 (1982)

12/ I.A. Arbuzova, P.V. Titov and L.G. Khandros, Metalofizika, 69 (1977), 83

13/ F. Nakamura, J. Kusui, Y. Shimizu and J. Takamur, J. Japan Inst. Met. 44, 1302-1311 (1980)

14/ J. Van Humbeeck, M. Chandrasekaran and L. Delaey, ISIJ International 29, 338-394 (1989)

15/ P. Rodriguez, Doctoral thesis, I.N.S.A. of Lyon, 204 pp.(1989)

16/ J. Van Humbeeck, L. Delaey and D. Roedolf, Proc. ICOMAT-86, Nara, Japan, ed. Japan Inst. of Metals, 863-867 (1987)

I7/ H. Warlimont and L. Delaey, Progress in Material Science 18, 1 (1974)

18/. R. Rapacioli and M. Ahlers, Acta Metall. 27, 777 (1979)

19/ W.M. Stobbs, R.J. Henderson and A.M. Crossley, Proc. ICOMAT-79, Cambridge, USA, 578-584 (1979)

110/ E. Kobus, S. Eucken and E. Hornbogen, Pract. Met. 26, 318-325 (1989)

$111 /$ D.P. Dunne, J. Van Humbeeck and L. Delaey, MRS Inter. Meeting on Advance Materials 9, 329-334 (1989)

112/ D.P. Dunne, J. Van Humbeeck and M. Chandrasekaran, Mater. Sci. Forum 56-58, 463$468(1990)$

/13/ P. Fisher, D. Dunne and N. Kennon, Proc. ICOMAT-86, Nara, Japan, ed. Japan Inst. of Metals, 946 (1986)

114/ J. Van Humbeek, D. Van Hulle, L. Delaey, J. Ortin, C. Segui and V. Torra, Trans. Jpn. Inst. Met. 28, 383 (1987)

115/ J. Ortin and A. Planes, Acta Metall. 36, 1873-1889 (1988)

116/ L. Cooreman, J. Van Humbeeck and L. Delaey, Acta Metall. 38, 2663-2666 (1990)

$117 /$ G. Scarsbrook, J.M. Cook and W.M. Stobbs, Metall. Trans. A 15, 1979 (1984)

118/ L. Delaey, M Chandrasekaran, M. Andrade and J. Van Humbeeck, Proc. Int. Conf. on Solid-Solid Transf., Pittsburgh 1981, ed. Met. Soc. of AIME, 1429-1453 (1982)

119/ L. Delaey, T. Suzuki and J. Van Humbeeck, Scripta Metall. 18, 899-903 (1984)

$120 /$ M.H. Wu and C.M. Wayman, Mater. Sci. Forum 56-58, 553-558 (1990)

Acknowledgements.- The authors thank Prof. K. Sugimoto, Kansai Univ., for providing the material and Dr. M. Chandrasekaran for his valuable suggestions. I. Hurtado wishes to acknowledge the Basque Government for providing him a scholarship. J. Van Humbeeck acknowledges the NFWO (National Foundation for Scientific Research). 